\title{
COMPORTAMENTO IN VITRO E CARACTERIZAÇÃO MORFOLÓGICA DE RAMULARIA AREOLA
}

Inês Roeder Nogueira Mendes ${ }^{1}$, João Paulo Ascari ${ }^{2 *}$, Jurandir Ambrósio ${ }^{3}$, Dejânia Vieira de Araújo $^{4}$, Rafael Sbruzzi Prieto ${ }^{5}$, Rodolfo Luis Cardoso Tavares ${ }^{5}$

\footnotetext{
${ }^{1}$ Mestranda no Programa de Pós-Graduação em Ambiente e Sistemas de Produção Agrícola - PPGASP, Universidade do Estado de Mato Grosso, Tangará da Serra - MT.

${ }^{2}$ Mestre em Ambiente e Sistemas de Produção Agrícola - PPGASP, Universidade do Estado de Mato Grosso, Tangará da Serra - MT. E-mail: joaoascari@hotmail.com

${ }^{3}$ Engenheiro Agrônomo, Prefeitura Municipal de Aripuanã, Aripuanã - MT.

${ }^{4}$ Professora Doutora em Agronomia - Fitopatologia, docente na Universidade do Estado de Mato Grosso, Tangará da Serra - MT.

${ }^{5}$ Graduando em Agronomia, Universidade do Estado de Mato Grosso, Tangará da Serra - MT.
}

RESUMO: O objetivo deste estudo foi avaliar os efeitos da temperatura e meios de cultura no índice de velocidade de crescimento micelial, produção de conídios e morfologia do fungo Ramularia areola. O estudo foi conduzido em condições de laboratório, com delineamento inteiramente casualizado, tendo quatro temperaturas e sete meios de cultura. Após o preparo de cada meio de cultura em placas de Petri, foi realizado a inoculação do fugo com discos de $2 \mathrm{~mm}$ de diâmetro contendo $R$. areola. As placas foram vedadas com filme PVC e incubadas com fotoperíodo de $12 \mathrm{~h}$ luz e $12 \mathrm{~h}$ escuro, com as respectivas temperaturas de cada tratamento. Foi avaliado o índice de velocidade de crescimento micelial (IVCM), número de conídios (NC) e características morfológicas de $R$. areola. Houve interação significativa entre os meios de cultura e temperatura para as variáveis IVCM e NC de $R$. areola, onde o meio que favoreceu o IVCM foi Arroz-Ágar (AA), enquanto que, o NC foi superior nos meios BDA e Suco vegetal - (V8). O aspecto morfológico do fungo sofreu alterações evidentes na temperatura de $24^{\circ} \mathrm{C}$ e em função dos meios de cultura. Com isso, verificou-se que as temperaturas 24 e $28^{\circ} \mathrm{C}$, os meios de cultura AA, BDA e V8 promoveram maior IVCM e NC de Ramularia areola.

Palavras-chave: Mancha de Ramulária. Meio de cultura. Temperatura.

\section{IN VITRO BEHAVIOR AND MORPHOLOGICAL CHARACTERIZATION OF RAMULARIA AREOLA}

\begin{abstract}
The fungus Ramularia areola presents destructive potential in the cotton crop, being economically important in Brazilian agribusiness, so it is necessary to know the behavior of this fungus. The objective of this study was to evaluate the effects of temperature and culture medium on the rate of mycelial growth rate, conidial production and morphology of the fungus Ramularia areola. The study was conducted under laboratory conditions, with a completely randomized design, with four temperatures and seven culture medium. After preparation of each culture medium in Petri plates, the inoculation was performed with $2 \mathrm{~mm}$
\end{abstract}

Cultura Agronômica, Ilha Solteira, v.26, n.3, p.456-468, 2017 
diameter discs containing $R$. areola. The plates were sealed with PVC film and incubated with photoperiod $12 \mathrm{~h}$ light and $12 \mathrm{~h}$ dark, with the respective temperatures of each treatment. The mycelial growth rate index (MGRT), number of conidia (NC) and morphological characteristics of $R$. areola were evaluated. There was significant interaction between the culture medium and temperature for the MGRT and NC variables of $R$. areola, where the culture medium that favored the MGRT was Rice-Agar (RA), while the NC was higher in the PDA and Vegetable Juice - (V8). The morphological aspect of the fungus underwent evident changes in the temperature of $24^{\circ} \mathrm{C}$ and in function of the culture medium. With this, it was found that temperatures of 24 and $28^{\circ} \mathrm{C}$, the culture medium RA, PDA and V8 promoted higher MGRT and NC of Ramularia areola.

Key words: Ramularia leaf spot. Culture medium. Temperature.

\section{INTRODUÇÃO}

Atualmente a mancha de ramulária (Ramularia areola (Atk.), [teleomorfo Mycosphaerella areola (J. Ehrlich \& F. A. Wolf)] é um relevante problema na cotonicultura brasileira, em especial na região dos cerrados. Como agravante da situação, os extensos cultivos de algodão, são realizados em sua maior parte, na forma de monocultura, e muitas vezes, utilizando cultivares com baixo grau de resistência a este fungo. Além disso, a região Centro-Oeste brasileira tem como características climáticas, elevados índices de precipitação pluviométrica e umidade relativa do ar, favoráveis ao progresso da mancha de ramulária (CIA et al., 2013; PIZZATO et al., 2014).

A doença causa desfolha precoce da planta, sendo mais severa no baixeiro, com isso, pode promover redução na produtividade do algodoeiro em cerca de $30 \%$ em cultivo safra e $20 \%$ em safrinha, quando medidas eficientes de controle não são adotadas (ASCARI et al., 2016). Para o manejo dessa doença é necessário a integração de práticas, utilizando cultivares com maior grau de resistência associado ao controle com fungicidas, pois somente o controle químico de forma isolada, pode necessitar de mais de 12 aplicações durante o ciclo da cultura (STEFANELO et al., 2016). Algumas técnicas culturais auxiliam no manejo dessa doença, tais como a adubação equilibrada e maior rigor nas aplicações de reguladores de crescimento, observando sempre a fase fisiológica da cultura (CIA; SALGADO, 2005).

Dessa forma, a busca por cultivares mais resistentes e produtivas tem sido intensificada nos estudos de melhoramento genético, e como ferramenta de auxílio a esses estudos, é fundamental o entendimento e domínio das técnicas de incubação e esporulação do patógeno em ambiente artificial (NOVAES et al., 2011). Pois, a capacidade epidemiológica de $R$. areola é bastante influenciada pela esporulação e pelos mecanismos de disseminação das estruturas do patógeno, sendo esses processos dependentes das condições climáticas de cada região, tais como a temperatura (PIZZATO et al., 2013; PIZZATO et al., 2014). 
Estudos em diferentes patossistemas vem sendo realizados visando o melhor desenvolvimento in vitro de fungos fitopatogênicos, como Hanada et al. (2002) com Mycosphaerella fijiensis, Melo e Reis (2010) analisando esporulação de Corynespora cassiicola, Galbieri et al. (2015) com isolados de $R$. areola e Gomes e Pena (2016) trabalhando com o fungo Quambalaria sp..

Apesar da grande importância de $R$. areola para a cotonicultura brasileira e mundial, são poucas as pesquisas visando a caracterização in vitro deste patógeno. Esses estudos buscam conhecer as características do fungo em cultivo in vitro, entender melhor seu desenvolvimento e esporulação, principalmente quando submetido as interferências ambientais, como condições de temperatura, luminosidade e substrato (GIROTTO et al., 2013; VOLPONI et al., 2014; GALBIERI et al., 2015). Por isso, almeja-se determinar a variabilidade patogênica de $R$. areola e suas características nas condições edafoclimáticas de Mato Grosso (MEHTA et al., 2016)

Entretanto, é fundamental o conhecimento laboratorial de características morfológicas das colônias, micélios e conídios do patógeno. Para isso, necessita-se determinar os substratos apropriados para o crescimento e desenvolvimento do fungo, que são bastante influenciados pela composição do meio de cultura e temperatura de incubação (DHINGRA; SINCLAIR, 1995). Conforme Curvelo et al. (2010), a temperatura ótima para a germinação e o desenvolvimento do tubo germinativo do fungo $R$. areola varia de 25 a $30^{\circ} \mathrm{C}$.

Com isso, o objetivo deste estudo foi avaliar os efeitos da temperatura e de meios de cultura no índice de velocidade de crescimento micelial, produção de conídios e morfologia do fungo Ramularia areola.

\section{MATERIAL E MÉTODOS}

O trabalho foi realizado no laboratório de Fitopatologia da Universidade do Estado de Mato Grosso, em Tangará da Serra - MT. O isolado de $R$. areola foi obtido de folhas de algodoeiro cultivado em condições de campo, com sintomas característicos da mancha de ramulária. $\mathrm{O}$ patógeno foi isolado de folhas de algodão, sendo inicialmente desinfestadas superficialmente com álcool $70 \%$ e hipoclorito de sódio 1\%, e lavadas com água destilada esterilizada. Após a identificação do fungo, estruturas com conídios foram retiradas das folhas e colocadas em placas de Petri contendo meio de cultura batata-dextrose-ágar (BDA), em seguida, foram cultivadas por cinco dias a $25^{\circ} \mathrm{C}\left( \pm 2^{\circ} \mathrm{C}\right)$ e fotoperíodo de $12 \mathrm{~h}$ para multiplicação do inóculo do fungo.

O experimento foi conduzido utilizado um delineamento inteiramente casualizado, com análise fatorial duplo ( 4 x 7), tendo quatro temperaturas e sete meios de cultura, com seis repetições, sendo cada repetição constituída por uma placa de Petri. As temperaturas foram determinadas dentro da amplitude térmica que favorece o desenvolvimento do patógeno em condições de campo, que varia entre 20 e $30^{\circ} \mathrm{C}$ (CURVELO et al., 2010). Portanto, foram consideradas as temperaturas de $20,24,28$ e $32^{\circ} \mathrm{C}$.

Cultura Agronômica, Ilha Solteira, v.26, n.3, p.456-468, 2017 
Os meios de cultura testados foram: I: BDA - Batata-Dextrose-Ágar (20 g de dextrose, $20 \mathrm{~g}$ de ágar, $500 \mathrm{~mL}$ de caldo de batata e $500 \mathrm{~mL}$ de água destilada); II: Suco Vegetal (V8) - meio de ágar com suco V8 (200 mL de V8-Campbel Soup Company, 3 g de $\mathrm{CaCO}_{3}, 17 \mathrm{~g}$ de ágar e $800 \mathrm{~mL}$ de água destilada); III: EMA - Extrato de malte ágar (25 g de extrato de malte, $17 \mathrm{~g}$ de ágar e $1.000 \mathrm{~mL}$ de água destilada); IV: EVA - Extrato vegetal ágar (20 g de dextrose, $20 \mathrm{~g}$ de ágar, $500 \mathrm{~mL}$ de extrato vegetal de folhas sadias do terço superior da planta de algodão com 40 dias após emergência e $500 \mathrm{~mL}$ de água destilada); V: KM - Kirchoff Modificado (30 g de dextrose, 0,5 g de asparagina $\mathrm{C}_{4} \mathrm{H}_{8} \mathrm{~N}_{2} \mathrm{O}_{3}, 1 \mathrm{~g}$ de sulfato de potássio $\mathrm{K}_{2} \mathrm{SO}_{4}, 0,5 \mathrm{~g}$ de sulfato de magnésio $\mathrm{MgSO}_{4} 7 \mathrm{H}_{2} \mathrm{O}, 20 \mathrm{~g}$ de ágar); VI: AA - Arroz ágar (500 $\mathrm{mL}$ do caldo de $50 \mathrm{~g}$ de arroz cozido, $20 \mathrm{~g}$ de dextrose e $20 \mathrm{~g}$ de ágar) e VII: DPA - Dextrose peptona ágar (10 $\mathrm{g}$ dextrose, $20 \mathrm{~g}$ de ágar, $2 \mathrm{~g}$ de peptona, 0,5 $\mathrm{g}$ de fosfato de potássio monobásico anidro $\mathrm{KH}_{2} \mathrm{PO}_{4}$ e $0,5 \mathrm{~g}$ de sulfato de magnésio $\mathrm{MgSO}_{4} 7 \mathrm{H}_{2} \mathrm{O}$ ).

Depois de preparados, os meios de cultura foram vertidos e frascos de vidro e autoclavados a $127^{\circ} \mathrm{C}$ por $20 \mathrm{~min}$. Sob condições assépticas em câmara de fluxo laminar, foi vertido $20 \mathrm{~mL}$ de cada meio em placas de Petri. Para a inoculação do fungo nos diferentes meios, foi retirado um disco de $2 \mathrm{~mm}$ de diâmetro de $R$. areola com cinco dias de incubação, e depositados no centro de cada placa de Petri, com os respectivos meios de cultura de cada tratamento. Todas as placas foram seladas com filme PVC e mantidas em incubadora tipo B.O.D, de acordo com a temperatura de cada tratamento, ambas em regime luminoso de $12 \mathrm{~h}$ luz por $12 \mathrm{~h}$ escuro.

As avaliações do índice de velocidade de crescimento micelial (IVCM) tiveram início 24 h após a incubação, sendo diariamente realizadas medições dos dois eixos ortogonais do diâmetro das colônias, com paquímetro digital. Com os dados de cada tratamento, foi calculado IVCM a partir da Eq. 1, descrita por Oliveira (1992):

(Eq.1)

$$
\mathrm{IVCM}=\sum \frac{(\mathrm{D}-\mathrm{Da})}{\mathrm{N}}
$$

Onde D - diâmetro médio atual da colônia (mm), Da - diâmetro médio da colônia do dia anterior (mm) e N - número de dias após a inoculação. A avaliação de IVCM foi finalizada no sexto dia de incubação, onde foi observado crescimento completo de uma das colônias.

Logo após a última avaliação do IVCM, foram realizadas as avaliações da produção de conídios. Para isso, retirou-se cinco discos de $5 \mathrm{~mm}$ de diâmetro das regiões centrais e laterais de cada colônia, e colocados em Becker de $20 \mathrm{~mL}$, contendo $10 \mathrm{~mL}$ de água destilada estéril e Tween-80 a 0,001\%, sendo agitado por dois minutos para desagregação dos conídios. Em cada placa de Petri foi realizada quatro contagens de esporos na câmara de Neubauer, contabilizando o número de esporos $\mathrm{mL}^{-1}$. Foram contabilizados apenas os esporos característicos de $R$. areola, conforme a descrição realizada por Volponi et al. (2014).

Para as características morfológicas das colônias do fungo $R$. areola, foi adaptada a metodologia de realizada por Sussel (2005). Para estimar a coloração da colônia foi realizado 
avaliações de coloração durante o crescimento do micélio em cada tratamento. $\mathrm{O}$ aspecto da colônia foi avaliado por observações do comportamento do crescimento micelial, considerando-se a densidade do micélio e altura da colônia do fungo. Na formação de setores, foi contado a quantidade média de setores formados pelas colônias em cada tratamento.

Os dados do índice de velocidade de crescimento micelial e da produção de conídios foram analisados pelo teste $\mathrm{F}$, seguido da análise de regressão $(\mathrm{p}<0,05)$ por meio do programa estatístico Sisvar (FERREIRA, 2011).

\section{RESULTADOS E DISCUSSÃO}

Houve interação significativa entre meios de cultura e temperaturas para as variáveis índice de velocidade de crescimento micelial (IVCM). O crescimento médio das colônias em todos os meios foi de $10,92 \mathrm{~mm} \mathrm{dia}^{-1}$, tendo o menor crescimento no meio BDA $(9,54 \mathrm{~mm}$ $\left.\operatorname{dia}^{-1}\right)$ e $\mathrm{KM}\left(8,83 \mathrm{~mm} \mathrm{dia}{ }^{-1}\right)$, e maior no meio AA $\left(13,30 \mathrm{~mm} \mathrm{dia}{ }^{-1}\right)$, onde este último, apresentou desenvolvimento completo na placa de Petri com seis dias após a incubação (Figura 1).

Ao analisar o efeito da temperatura, percebe-se que a incubação a $32^{\circ} \mathrm{C}$ restringiu a velocidade de crescimento micelial de $R$. areola em todos os meios de cultura. Com exceção dos meios BDA (maior IVCM a 24 e $28^{\circ} \mathrm{C}$ ) e KM (maior IVCM a $28^{\circ} \mathrm{C}$ ), os demais meios de cultura tiveram maior IVCM nas temperaturas variando entre 20 e $28^{\circ} \mathrm{C}$ (Figura 1). Para ser mais preciso, a partir do ponto de máxima (PM) podemos verificar a temperatura exata em que ocorreu maior IVCM em função de cada meio, sendo 25,60; 24,35; 24,58; 23,99; 25,42; 24,42 e $23,91^{\circ} \mathrm{C}$ para BDA, V8, EMA, EVA, KM, AA e DPA, respectivamente.

Em relação a temperatura, a partir dos dados observados neste estudo no cultivo in vitro da fase assexual do fungo (Ramularia areola), constou-se maior desenvolvimento em uma faixa de temperatura variando entre 20 e $28^{\circ} \mathrm{C}$. Tais resultados estão em conformidade com Mehta et al. (2016), onde realizaram o cultivo in vitro da fase sexual deste mesmo fungo (Mycosphaerella areola) utilizando temperatura de $21^{\circ} \mathrm{C}$, considerada adequada.

A partir deste comportamento do fungo perante as condições de temperatura, podemos também relacionar com o comportamento da doença a campo. Devido ao fungo ter sido favorecido por temperaturas mais amenas em ambiente controlado, pode dar suporte aos resultados verificados por Ascari et al. (2016a; 2016b), onde encontraram os maiores valores de área abaixo da curva de progresso de severidade de $R$. areola no terço inferior das plantas. Que de acordo com Johnson et al. 2013, o microclima nessa região da planta apresenta condições térmicas variando entre 20 e $30^{\circ} \mathrm{C}$, sendo ideal ao desenvolvimento e esporulação do patógeno. 

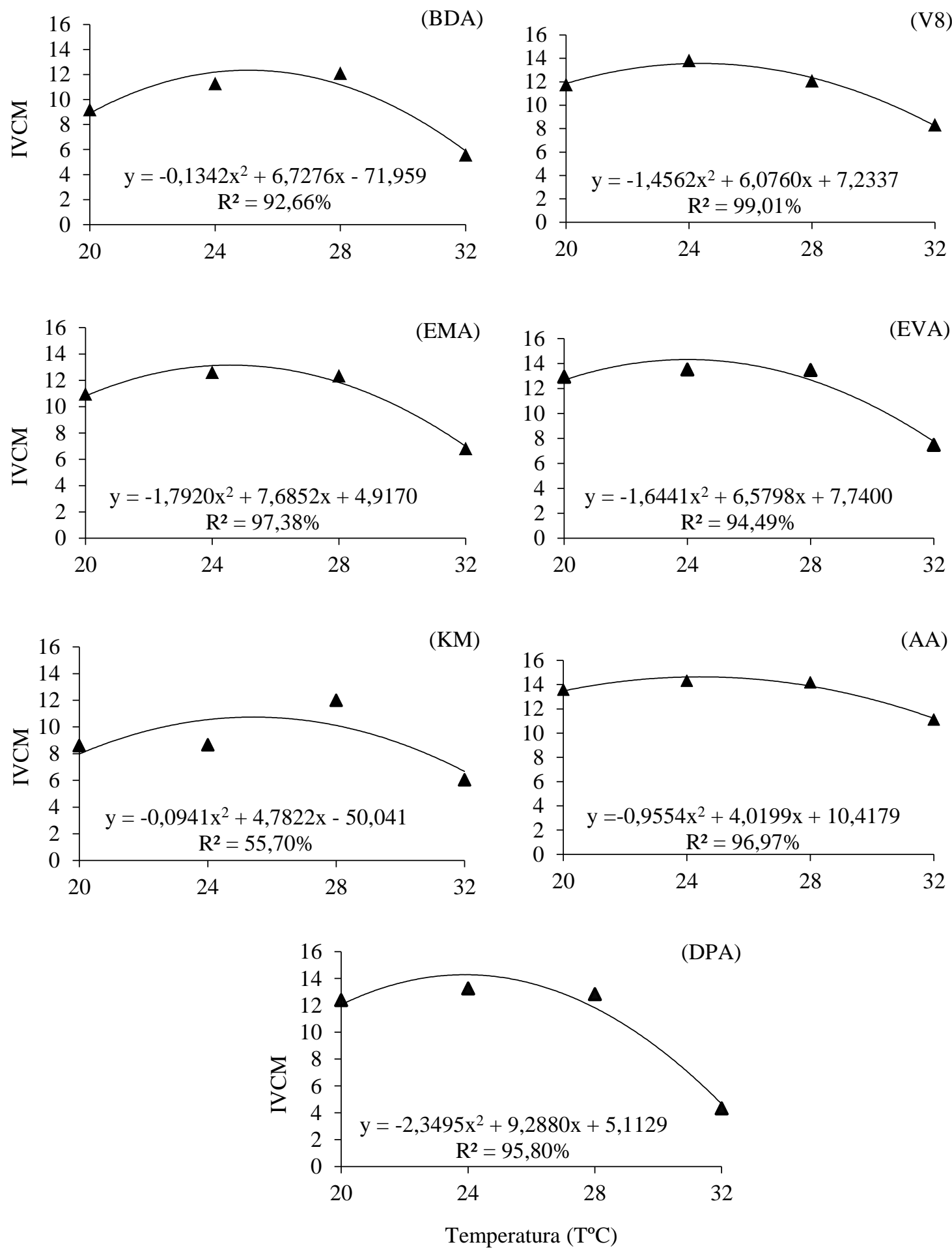

Figura 1. Índice de velocidade de crescimento micelial (IVCM) de Ramularia aerola com os meios Batata-dextrose-ágar (BDA); Suco Vegetal (V8); Extrato de Malte Ágar (EMA); Extrato Vegetal Ágar (EVA); Kirchoff Modificado (KM); Arroz Ágar (AA); DextrosePeptona-Ágar (DPA) nas temperaturas de $20,24,28$ e $32^{\circ} \mathrm{C}\left( \pm 1^{\circ} \mathrm{C}\right)$. 

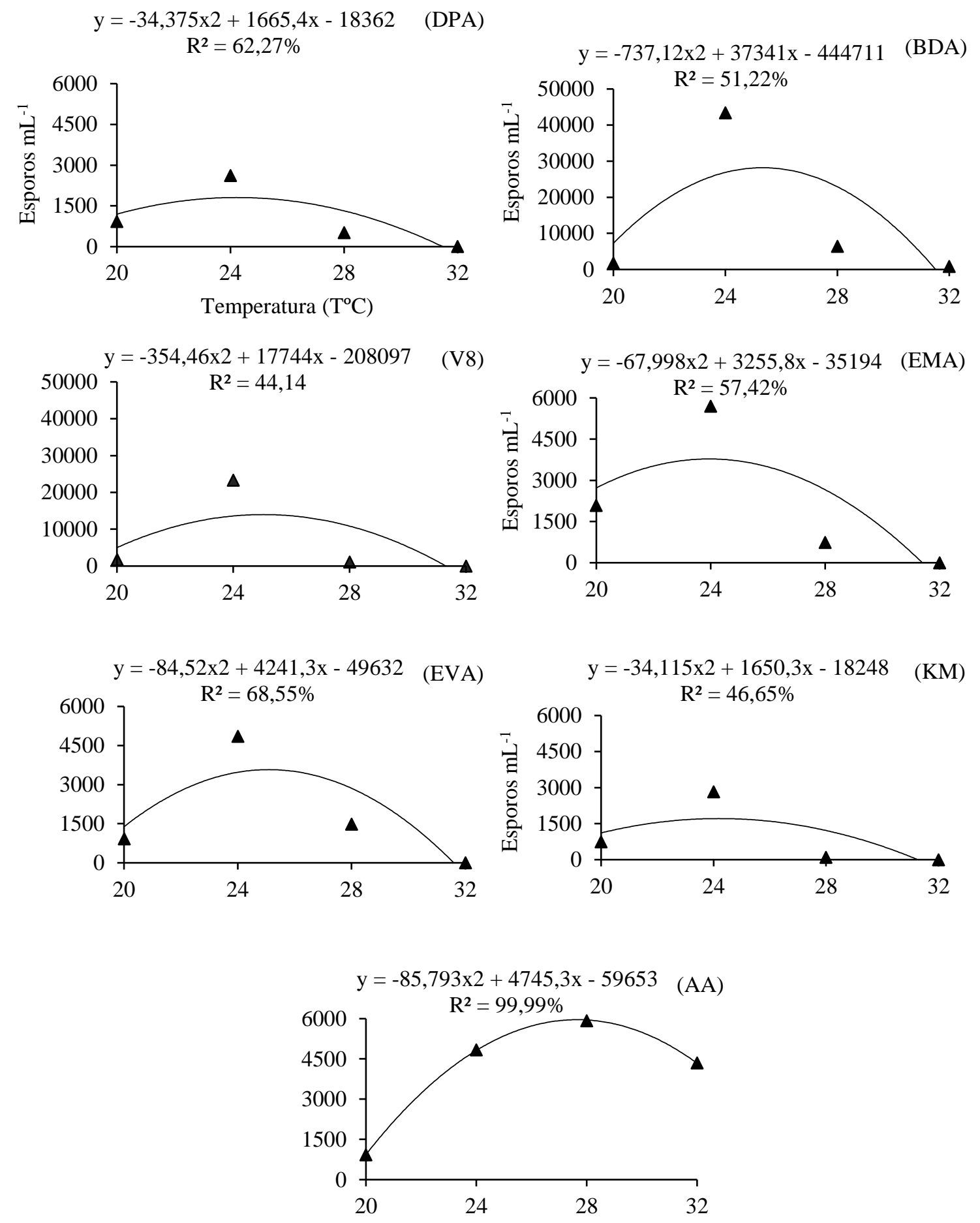

Figura 2. Número de conídios do isolado de Ramularia aerola com os meios Batata-dextroseágar (BDA); Suco Vegetal (V8); Extrato de Malte Ágar (EMA); Extrato Vegetal Ágar (EVA); Kirchoff Modificado (KM); Arroz Ágar (AA); Dextrose-Peptona-Ágar (DPA) e temperaturas de $20,24,28$ e $32^{\circ} \mathrm{C}\left( \pm 1^{\circ} \mathrm{C}\right)$.

Em relação aos meios de cultura, os resultados encontrados diferem dos observados por Gomes e Pena (2016), pois estudando o fungo Quambalaria eucalypti (M.J. Wingf., Crous \& Cultura Agronômica, Ilha Solteira, v.26, n.3, p.456-468, 2017 
W.J. Swart) encontraram maior IVCM no meio BDA, seguido do meio V8. Essas diferenças conforme os mesmos autores, ocorrem devido composição nutricional característica de cada meio de cultura, pois as mesmas podem ou não promover estímulos ao desenvolvimento e crescimento do micélio.

Ocorreu interação significativa entre os meios de cultura e as temperaturas para a variável número de conídios (NC). Os meios de cultura que influenciaram em maior $\mathrm{NC}$ na temperatura de $24^{\circ} \mathrm{C}$ foram $\mathrm{BDA}$ e $\mathrm{V} 8$, respectivamente, enquanto que a $28^{\circ} \mathrm{C}$ os meios $\mathrm{BDA}$ e AA tiveram maior produção de conídios. Os demais meios apresentaram baixa indução a esporulação do fungo, já no meio KM não ocorreu produção de esporos. Por esse motivo, os meios EMA, EVA, KM, AA e DPA não são indicados para o cultivo in vitro de deste isolado de $R$. areola em condições de laboratório. O efeito da temperatura foi evidente somente nos meios BDA e V8, que tiveram maior NC na temperatura de $24^{\circ} \mathrm{C}$ (Figura 2).

Observou-se que os meios de cultura que favoreceram o IVCM (meio AA) não foram os mesmos que estimularam a esporulação e produção de conídios (meios BDA e V8) de $R$. areola. Quanto a isso, Nozaki et al. (2004) comentaram que nem sempre os mesmos meios favorecem ao mesmo tempo a produção de hifas e conídios do fungo, pois de acordo com Gomes e Pena (2016), as diferenças nutritivas e a complexidade dos carboidratos influenciam nas fases de desenvolvimento do fungo. Ainda de acordo com Cruz et al. (2009), a composição e concentração de nutrientes no substrato, o requerimento nutricional e a variabilidade fisiológica do isolado, além das condições ambientais, podem influenciar a multiplicação de conídios de fungos fitopatogênicos.

Para Galbieri et al. (2015), além das características já mencionadas acima, o potencial de esporulação depende do isolado e da temperatura, sendo que, nos estados de Mato Grosso e Goiás, a maior esporulação de $R$. areola ocorreu na temperatura de $23^{\circ} \mathrm{C}$, não tendo produção de conídios em temperaturas próximas de $33^{\circ} \mathrm{C}$. Assim como verificado neste estudo, isso prova que este fungo não se desenvolve adequadamente em altas temperaturas, pois, além do reduzido crescimento micelial, não produz estruturas de disseminação.

A adição de folha de algodão na composição do meio de cultura, como no EVA, esperava-se um estímulo na esporulação do fungo, porém, isso não ocorreu (Figura 2). Essa mesma técnica foi relatada por Nozaki et al. (2004), onde verificaram a influência do meio de cultura no crescimento micelial e produção de picnídios de Diaporthe citri.

Os efeitos das temperaturas não foram evidentes sobre a morfologia de $R$. areola, porém, houve grande variação morfológica entre os meios de cultura testados. Com base na Tabela 1 e Figura 3, é possível verificar as características descritivas do fungo em função de cada meio de cultura, onde observou-se que apesar de diferenças quanto a coloração, os meios de cultura BDA, V8 e DPA apresentaram alta produção e denso micélio. 
Tabela 1. Caracterização morfológica da colônia de Ramularia areola em diferentes meios de cultura na temperatura de $24^{\circ} \mathrm{C}$

\begin{tabular}{lccc}
\hline Meio de cultura & Coloração da colônia & Aspecto & Setores \\
\hline BDA & Branco & Alto-Denso & 2,33 \\
V8 & Branco-rosado & Alto-Denso & 5,00 \\
EMA & Branco & Alto-Ralo & 2,16 \\
EVA & Branco & Ralo & 0 \\
KM & Rosa & Ralo & 0 \\
AA & Branco & Ralo & 0 \\
DPA & Branco-rosado & Alto-Denso & 5,80 \\
\hline
\end{tabular}

${ }^{1}$ Batata-dextrose-ágar (BDA); Suco Vegetal (V8); Extrato de Malte Ágar (EMA); Extrato Vegetal Ágar (EVA); Kirchoff Modificado (KM); Arroz Ágar (AA); Dextrose-Peptona-Ágar (DPA).

Segundo Volponi et al. (2014), essa variação no aspecto morfológico pode ocorrer quando se faz uso de subcultivos repetidos do mesmo isolado, e também quando se utiliza diferentes meios de cultura, pois é possível que o fungo sofra alterações nas características culturais e morfológicas.

Neste estudo, a colônia de $R$. areola que apresentou maior NC foi no meio BDA tendo coloração esbranquiçada (Figura 3). Conforme Volponi et al. (2014), as colônias que produzem mais conídios, são as que mudam da coloração rosa claro para a cor branca. Essa variação entre os meios de cultura ainda não foi relatada na literatura para $R$. areola, apesar disso, já se sabe que os isolados deste fungo de diferentes regiões geográficas variam quanto as características morfologias e a esporulação (VOLPONI et al., 2014; GALBIERI et al., 2015; MEHTA et al., 2016).

Com isso, ficou evidente a influência que a temperatura e as diferenças nutricionais de substratos podem exerceram sobre o desenvolvimento e morfologia do fungo $R$. areola em condições de laboratório. Esses dados podem auxiliar nas explicações referentes ao comportamento deste patógeno em condições de campo, influenciando nas tomadas de decisões e escolha das práticas de manejo.

Cultura Agronômica, Ilha Solteira, v.26, n.3, p.456-468, 2017 

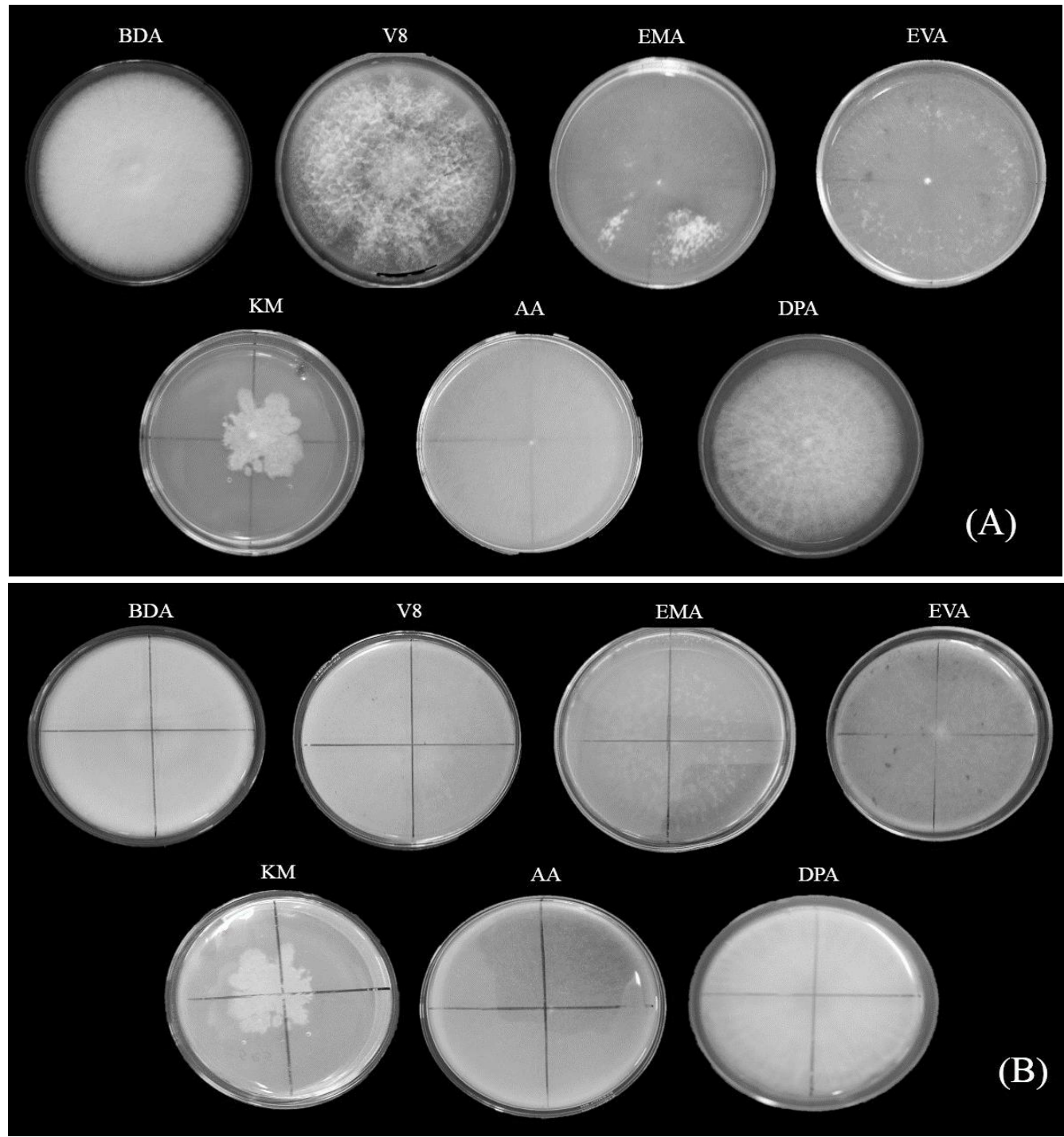

Figura 3. Aspecto morfológico e coloração de colônias de Ramularia aerola na superfície (A) e abaixo (B) da placa de Petri, com os meios Batata-dextrose-ágar (BDA); Suco Vegetal (V8); Extrato de Malte Ágar (EMA); Extrato Vegetal Ágar (EVA); Kirchoff Modificado (KM); Arroz Ágar (AA); Dextrose-Peptona-Ágar (DPA).

\section{CONCLUSÃO}

As temperaturas de 24 e $28^{\circ} \mathrm{C}$ apresentaram maior índice de velocidade e crescimento micelial e número de conídios de Ramularia areola.

O meio de cultura que mais estimulou o índice de velocidade de crescimento micelial foi o Arroz-Ágar, enquanto que o número de conídios foi maior com os meios Batatadextrose-ágar (BDA) e Suco Vegetal - V8.

$\mathrm{O}$ aspecto morfológico de Ramularia areola foi afetado pelos diferentes meios de cultura, não tendo efeitos da temperatura. 


\section{REFERÊNCIAS BIBLIOGRÁFICAS}

ASCARI, J. P.; ARAÚJO, D. V.; DIAS, L. D. E.; BAGATINI, G. J.; MENDES, I. R. N. Severity of ramularia leaf spot and seed cotton yield in different sowing times. Revista Caatinga, Mossoró, v. 29, n. 3, p.603-610, 2016a.

ASCARI, J. P.; MENDES, I. R. N.; SILVA, V. C.; ARAÚJO, D. V. Ramularia leaf spot severity and effects on cotton leaf area and yield. Pesquisa Agropecuária Tropical, Goiânia, v. 46, n. 4, p.434-441, $2016 \mathrm{~b}$.

CIA, E.; FUZATTO, M. G.; KONDO, J. I.; OHL, G. A.; GALBIERI, R. Reação de genótipos de algodoeiro à mancha de ramulária em diferentes épocas e ambientes. Summa Phytopathologica, Botucatu, v. 39, n. 3, p.193-197, 2013.

CIA, E.; SAlGADO, C. L. Doenças do algodoeiro. In: KIMATI, H.; AMORIM, L.; REZENDE, J. A. M.; BERGAMIN FILHO, A; CAMARGO, L. E. A. (eds.). Manual de Fitopatologia: Doenças de plantas cultivadas. São Paulo. Agronômica Ceres, 2005. cap. 6, p.41-52.

CRUZ, M. F. A.; PRESTES, A. M.; MACIEL, J. L. N. Esporulação de Pyricularia grisea em diferentes meios de cultura e regimes de luz. Ciência Rural, Santa Maria, v. 39, n. 5, p.15621564, 2009.

CURVElO, C. R. S.; RODRIGUES, P. G. B.; BERGER, P. G.; REZENDE, D. C. Microscopia eletrônica de varredura do processo infeccioso de Ramularia areola em folhas de algodoeiro. Tropical Plant Pathology, Brasília, v. 35, n. 2, p.108-113, 2010.

DHINGRA, O.; SINCLAIR, J. B. Basic Plant Pathology Methods. Boca Raton: CRC Press Inc., $1995.434 \mathrm{p}$.

FERREIRA, D. F. Sisvar: a computer statistical analysis system. Ciência e Agrotecnologia, Lavras, v. 35, n. 6, p.1039-1042, 2011.

GALBIERI, R.; CIA, E.; MORELLO, C. L.; FANAN, S.; JUNIOR, E. R. A.; KOBAYASTI, L. Ramularia areola sporulation potential in Brazilian cotton. Summa Phytopathologica, Botucatu, v. 41, n. 3, p.233-235, 2015.

GIROTTO, L.; MARANGONI, M. S.; MATOS, J. N.; GALBIERI, R.; ALMEIDA, W. P.; MEHTA, Y. R. Identifiation of phenotypic and genotypic variability among the isolates of Ramularia areola of Brazilian cotton. American Journal of Plant Sciences, Irvine, v. 4, n. 9, p.1893-1898, 2013.

GOMES, E. M. C.; PENA, R. C. M. Isolamento, caracterização morfológica e avaliação do crescimento micelial e esporulação em diferentes meios de cultura de cepas do fungo Quambalaria sp. Biota Amazônia, Macapá, v. 6, n. 4, p.59-63, 2016.

Cultura Agronômica, Ilha Solteira, v.26, n.3, p.456-468, 2017 
HANADA, R. E.; GASPAROTTO, L.; PEREIRA, J. C. R. Esporulação de Mycosphaerella fijiensis em diferentes meios de cultura. Fitopatologia Brasileira, Brasília, v. 27, n. 2, p.170$173,2002$.

JOHNSON, I.; RAMJEGATHESH, R.; KARTHIKEYAN, M.; CHIDAMBARAM, P. Epidemiol ogy of grey mildew and Alternaria blight of cotton. Archives of Phytopathology and Plant Protection, Camberra, v. 46, n. 18, p.2216-2223, 2013.

MEHTA, Y. R.; GALBIERI, R.; MARANGONI, M. S.; BORSATO, L. C.; RODRIGUES, H. P.; PEREIRA, P.; MEHTA, A. Mycosphaerella areola - The Teleomorph of Ramularia areola of cotton in Brazil, and its epidemiological significance. American Journal of Plant Sciences, Irvine, v. 7, n. 10, p.1415-1422, 2016.

MELO, M. M.; REIS, E. M. Effect of substrates, light and filter paper on Corynespora cassiicola sporulation. Summa Phytopathologica, Botucatu, v. 36, n. 3, p.251-253, 2010.

NOVAES, T. G.; ALMEIDA, W. P.; SCHUSTER, I.; AGUIAR, P.; MEHTA, Y. R. Herança de resistência do algodoeiro a Ramularia areola. Summa Phytopathologica, Botucatu, v. 37, n. 2, p.150-152, 2011.

NOZAKI, M. H.; CAMARGO, M.; BARRETO, M. Caracterização de Diaporthe citri em diferentes meios de cultura, condições de temperatura e luminosidade. Fitopatologia Brasileira, Brasília, v. 29, n. 4, p.429-432, 2004.

OLIVEIRA, J. A. Efeito do tratamento fungicida em sementes e no controle de tombamento de plântulas de pepino (Cucumis sativas L.) e pimentão (Capsicum annanum L.). Ciência e Prática, Bebedouro, v. 16, n. 1, p.42-47, 1992.

PIZZATO, J. A.; ARAÚJO, D. V.; SERAFIM, M. E.; ARAÚJO, K. L.; DALLACORT, R.; GÍLIO, T. A. S.; JÚNIOR, J. R.; MACIEL, V. A. Epidemiologic study of Ramularia areola under different soil covers and spacings, for cotton crops. American Journal of Plant Sciences, Irvine, v. 4, n. 11, p.2049-2059, 2013.

PIZZATO, J. A.; ARAÚJO, D. V.; GALVANIN, E. A. S.; JÚNIOR, J. R.; MATOS, A. N. A.; VECCHI, M.; ZAVISLAK, F. D. Geostatistics as a methodology for studying the spatiotemporal dynamics of Ramularia areola in cotton crops. American Journal of Plant Sciences, Irvine, v. 5, n. 9, p.2472-2479, 2014.

STEFANELO, M. S.; OHL, G. A.; TAKIZAWA, E. K. Ramularia areola: Agressiva e Frequente. Revista Cultivar - Grandes Culturas, Pelotas, v. 16, n. 201, p.11-13, 2016.

SUSSEL, A. A. B. Caracterização de isolados de Colletotrichum legenarium, agente causal da antracnose da cucurbitáceas. 2005. 68 f. Dissertação (Mestrado em Agronomia, -Fitopatologia) - Universidade de São Paulo, Escola de Agronomia Luiz de Queiroz, Piracicaba, 2005.

VOLPONI, J.; MATOS, J. N.; GIROTTO, L.; MARANGONI, M. S.; GALBIERI, R.; MEHTA, Y. R. Spore Types and Spore Production of Ramularia areola for Screening Cotton

Cultura Agronômica, Ilha Solteira, v.26, n.3, p.456-468, 2017 
Germplasm for Resistance. American Journal of Plant Sciences, Irvine, v. 5, n. 1, p.24132417, 2014. 